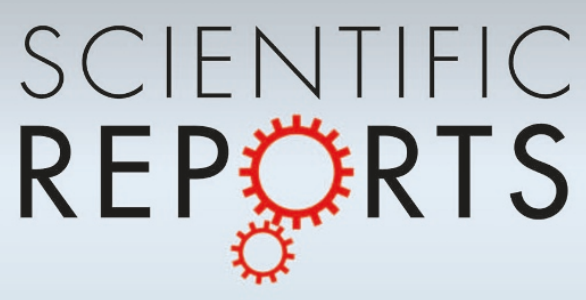

OPEN

SUBJECT AREAS:

HETEROGENEOUS

CATALYSIS

MATERIALS FOR ENERGY AND

CATALYSIS

BIOFUELS

CATALYST SYNTHESIS

Received

23 April 2013

Accepted

12 September 2013

Published

2 October 2013

Correspondence and requests for materials should be addressed to X.G.L. (xingang_li@tju. edu.cn) or N.T. (tsubaki@eng.utoyama.ac.jp)

\section{Tuning interactions between zeolite and supported metal by physical-sputtering to achieve higher catalytic performances}

\author{
Xin-Gang Li 1,2,3, Cheng Liu' ${ }^{1,2,3}$, Jian Sun ${ }^{4}$, Hui Xian ${ }^{1,5}$, Yi-Sheng Tan ${ }^{6}$, Zheng Jiang ${ }^{7}$, Akira Taguchi ${ }^{8}$, \\ Mitsuhiro Inoue ${ }^{8}$, Yoshiharu Yoneyama ${ }^{4}$, Takayuki $\mathrm{Abe}^{8}$ \& Noritatsu Tsubaki ${ }^{4,9}$
}

'School of Chemical Engineering \& Technology, Tianjin University, Tianjin, 300072, PR China, ${ }^{2}$ Tianjin Key Laboratory of Applied Catalysis Science \& Technology, 300072, PR China, ${ }^{3}$ The Synergetic Innovation Center of Chemistry and Chemical Engineering of Tianjin, Tianjin, 300072, PR China, ${ }^{4}$ Department of Applied Chemistry, School of Engineering, University of Toyama, Gofuku 3190 , Toyama 930-8555, Japan, ${ }^{5}$ Pei-Yang Distillation Engineering Limited Company, Tianjin, 300072, PR China, ${ }^{6}$ State Key Laboratory of Coal Conversion, Institute of Coal Chemistry, Chinese Academy of Science, Taiyuan, 03000 1, PR China, 7 Shanghai Synchrotron Radiation Facility, Shanghai Institute of Applied Physics, Chinese Academy of Sciences, Shanghai, 201204, PR China, ${ }^{8} \mathrm{Hydrogen}$ Isotope Research Center, University of Toyama, Gofuku 3190, Toyama 930-8555, Japan, ${ }^{9}$ JST, ACT-C, 102-8666, Tokyo, Japan.

To substitute for petroleum, Fischer-Tropsch synthesis (FTS) is an environmentally benign process to produce synthetic diesel (n-paraffin) from syngas. Industrially, the synthetic gasoline (iso-paraffin) can be produced with a FTS process followed by isomerization and hydrocracking processes over solid-acid catalysts. Herein, we demonstrate a cobalt nano-catalyst synthesized by physical-sputtering method that the metallic cobalt nano-particles homogeneously disperse on the H-ZSM5 zeolite support with weak Metal-Support Interactions (MSI). This catalyst performed the high gasoline-range iso-paraffin productivity through the combined FTS, isomerization and hydrocracking reactions. The weak MSI results in the easy reducibility of the cobalt nano-particles; the high cobalt dispersion accelerates $n$-paraffin diffusion to the neighboring acidic sites on the H-ZSM5 support for isomerization and hydrocracking. Both factors guarantee its high CO conversion and iso-paraffin selectivity. This physical-sputtering technique to synthesize the supported metallic nano-catalyst is a promising way to solve the critical problems caused by strong MSI for various processes.

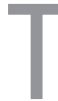
here is a recognized need to synthesize clean liquid fuel, including gasoline and diesel, from renewable biomass to solve the global petroleum shortage crisis and also realize a green process by decreasing $\mathrm{CO}_{2}$ emissions. Fischer-Tropsch synthesis $(\mathrm{FTS})^{1}$ is a promising way to meet this demand using syngas $(\mathrm{CO}+$ $\mathrm{H}_{2}$ ), which is easily derived from biomass, garbage, and shale gas ${ }^{2}$, to produce environmentally benign sulfur-free liquid fuels ${ }^{3}$. It not only avoids the acid rain and photochemical smog but also solves the sulfur-poison problem for catalytic aftertreatment systems of automobiles. For example, the conventional Lean $\mathrm{NO}_{\mathrm{x}}$ Trap catalysts, which are readily poisoned by sulfur, can only be commercialized on lean-burn engines using sulfur-free fuels ${ }^{4}$. The FTS reaction usually uses a Co, Ru or Fe based catalyst ${ }^{5}$. The synthetic diesel, i.e. long chain normal paraffin ( $n$-paraffin), is the dominant FTS product, and the carbon number distribution is controlled by the AndersonSchulz-Flory (ASF) $l a w^{5}$. It is difficult to disobey this law and achieve selective and specified carbon numbers, e.g. gasoline range $\left(\mathrm{C}_{5}-\mathrm{C}_{11}\right)$ iso-paraffin products.

Many efforts have been made to obtain these gasoline range iso-paraffin products from FTS. For example, the Shell SMDS plant in Malaysia used a separate reactor containing solid acid catalysts to isomerize and hydrocrack the long chain $n$-paraffin produced from FTS ${ }^{6}$. Theoretically, if the FTS and the subsequent isomerization/ hydrocracking processes occur on a combined catalyst including both FTS and acidic catalysts under the same reaction conditions, only one reactor is needed. This design will decrease economic cost significantly. For such a consecutive reaction, its catalytic performance can be remarkably enhanced by keeping these two kinds of sites close to each other to improve their dispersion ${ }^{7}$. Here, we expect that the produced long $n$-paraffin products at the FTS sites can be shortened and branched to iso-paraffin at the adjacent acidic sites. Accordingly, the iso-paraffin products (premier gasoline) are efficiently synthesized by one step.

Zeolite, such as H-ZSM5, is one of the conventional solid acid catalysts possessing good hydrocracking and isomerization performances ${ }^{8}$. Therefore, some efforts have been done to synthesize iso-paraffin from syngas using 


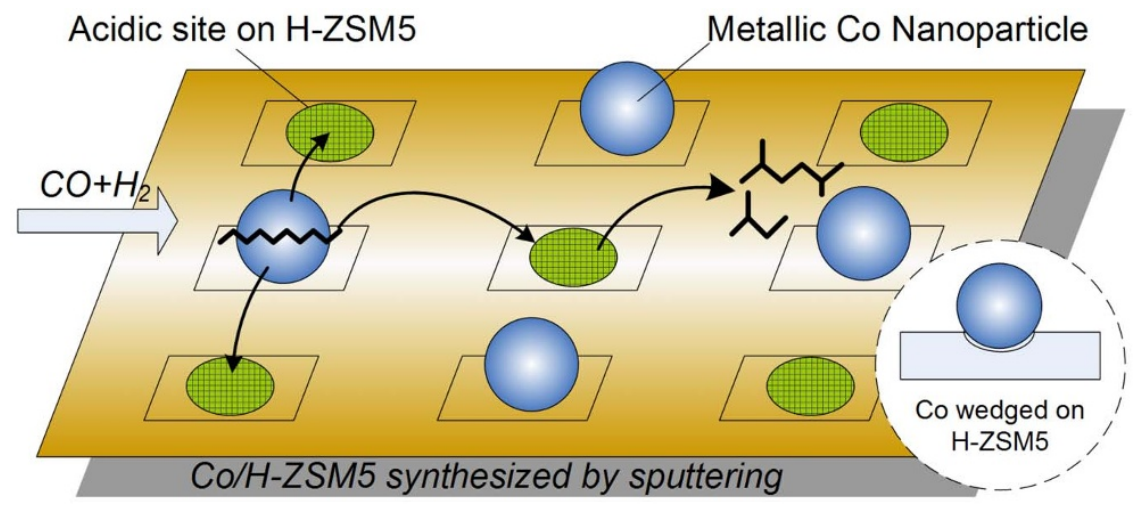

Figure $1 \mid$ Possible reaction routes of the Co/H-ZSM5-S catalyst during the FTS, isomerization and hydrocracking reactions.

the physical-mixed FTS and zeolite catalysts ${ }^{9-11}$. However, a lot of the linear hydrocarbons directly escaped from the FTS sites due to the uneven distribution of the FTS sites and acidic sites. As a result, the formed FTS wax was easily deposited on the FTS active sites, which seriously caused catalytic deactivations. Therefore, this methodology is insufficient for the synthesis of the commercial synthetic gasoline. Directly loading a FTS catalyst onto an acidic zeolite support by the impregnation method was also reported, but only a low FTS activity was achieved ${ }^{12,13}$. The strong MSI between the FTS catalyst and the zeolite support severely inhibited the reduction of the FTS catalyst precursor, i.e. the metal oxides. Depositing cobalt cations into micropores of zeolite by the ion-exchange method ${ }^{14}$ is also inconvenient because the strong interactions between the cobalt cations and zeolites would require a high temperature to reduce them to the metals, e.g. above $700^{\circ} \mathrm{C}^{15}$. Such a high temperature will further destroy the zeolite frameworks in the presence of water.

Recently, we proposed one kind of the encapsulated catalysts by coating an acidic zeolite onto a FTS catalyst pellet for the direct synthesis of iso-paraffin from syngas ${ }^{16-18}$. These tailor-made encapsulated catalysts can break the ASF law, reduce the heavy hydrocarbon products, and enhance the selectivity of the gasoline range paraffin, especially iso-paraffin. However, it hardly avoids the formation of the cracks and defects on the zeolite membrane during the reactions due to the fraction between the catalyst pellets and the thermal expansion caused by heat.

To overcome these problems, herein, we demonstrate a facile drymethod to synthesize H-ZSM5 supported metallic cobalt nanoparticles using a hexahedral-barrel sputtering system ${ }^{19}$. This system has been employed to deposit nano-particles, such as $\mathrm{Pt}, \mathrm{Ru}, \mathrm{Pt}-\mathrm{Ru}$ alloy and $\mathrm{TiO}_{2}$, onto various inert powder supports acting as an electrode catalyst for fuel cell or a catalyst for $\mathrm{CO}_{2}$ methanation ${ }^{20-23}$. Unlike the common physical-sputtering devices, which sputter atomic clusters from an aimed target onto a glass or ceramic disc, our rotated polygonal-barrel sputtering system can deposit nanoparticles onto the powders homogeneously ${ }^{20,21}$; the other advantage is the narrow and controllable size distribution of the nano-particles through varying its ac power levels ${ }^{21}$. This technique provides a new possibility to synthesize nano-catalysts with weak MSI, since the nano-particles are wedged onto the support by physical forces. The possible reaction routes of this catalyst during the FTS, isomerization and hydrocracking reactions are proposed in Fig. 1.

\section{Results}

Preparation and characterizations. Differently from catalytically inert support powders until now, here, cobalt nano-particles were directly sputtered from the metallic Co target onto the acidic $\mathrm{H}$ ZSM5 zeolite powders, and the obtained catalyst was denoted as $\mathrm{Co} / \mathrm{H}-\mathrm{ZSM} 5-\mathrm{S}$. For comparison, the other H-ZSM5 supported cobalt catalyst was also synthesized by a conventional wet impregnation method, and was denoted as $\mathrm{Co} / \mathrm{H}-\mathrm{ZSM} 5-\mathrm{I}$. The $\mathrm{Co} /$ H-ZSM5-S and Co/H-ZSM5-I catalysts had the same cobalt weight loading, i.e. $7.0 \mathrm{wt} \%$, and presented metallic luster and green-yellow appearances, respectively (see Supplementary Fig. S1 online). It implies the presence of the metallic cobalt species on the $\mathrm{Co} / \mathrm{H}$ ZSM5-S catalyst, whereas no cobalt-related phase was detected from the XRD pattern (see Supplementary Fig. S2 online). Fig. 2 shows their High Resolution Transmission Electron Microscopy (HR-TEM) images. For the Co/H-ZSM5-I catalyst, the cobalt
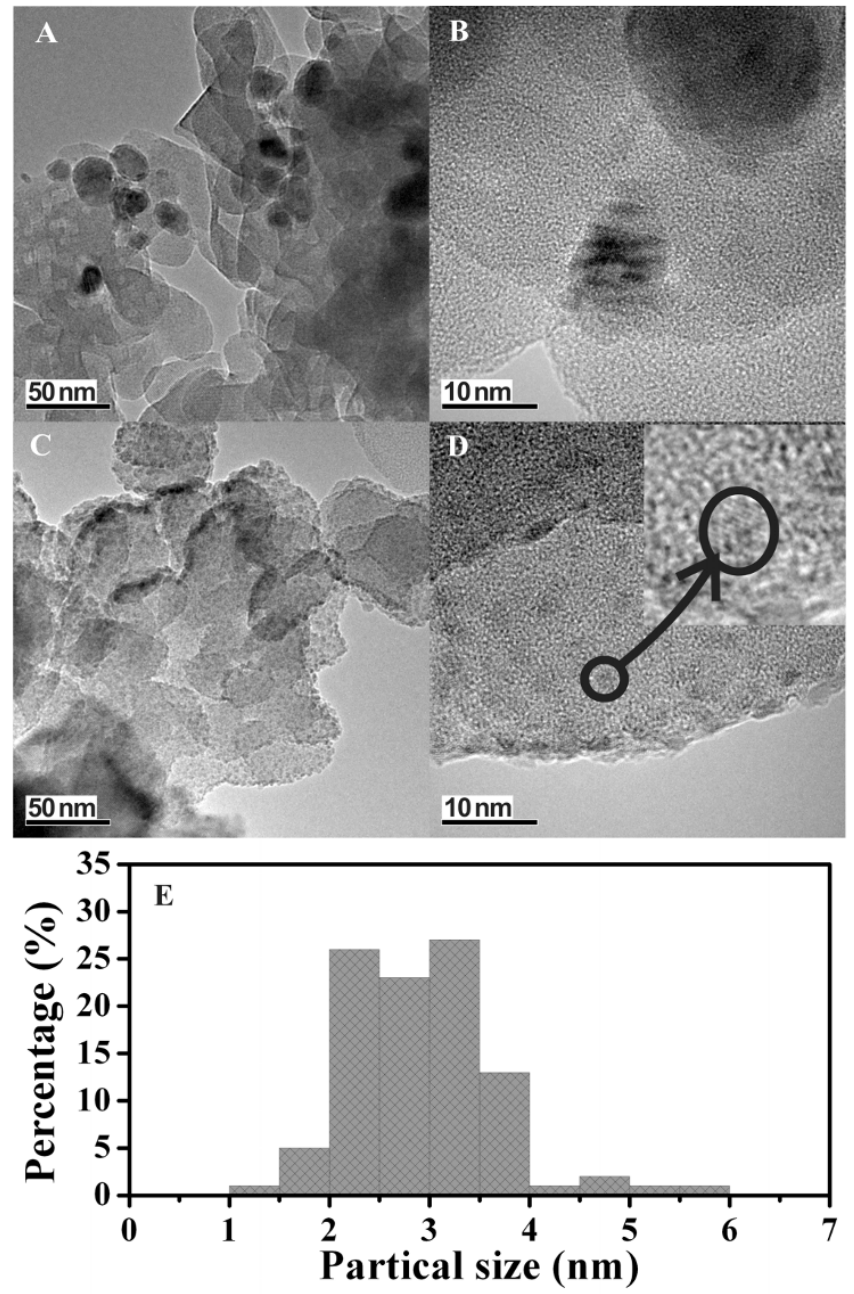

Figure $2 \mid$ HR-TEM images of the Co/H-ZSM5-I (A, B) and Co/H-ZSM5$\mathrm{S}(\mathrm{C}, \mathrm{D})$ catalysts; and the size distribution of the Co/H-ZSM5-S (E). 

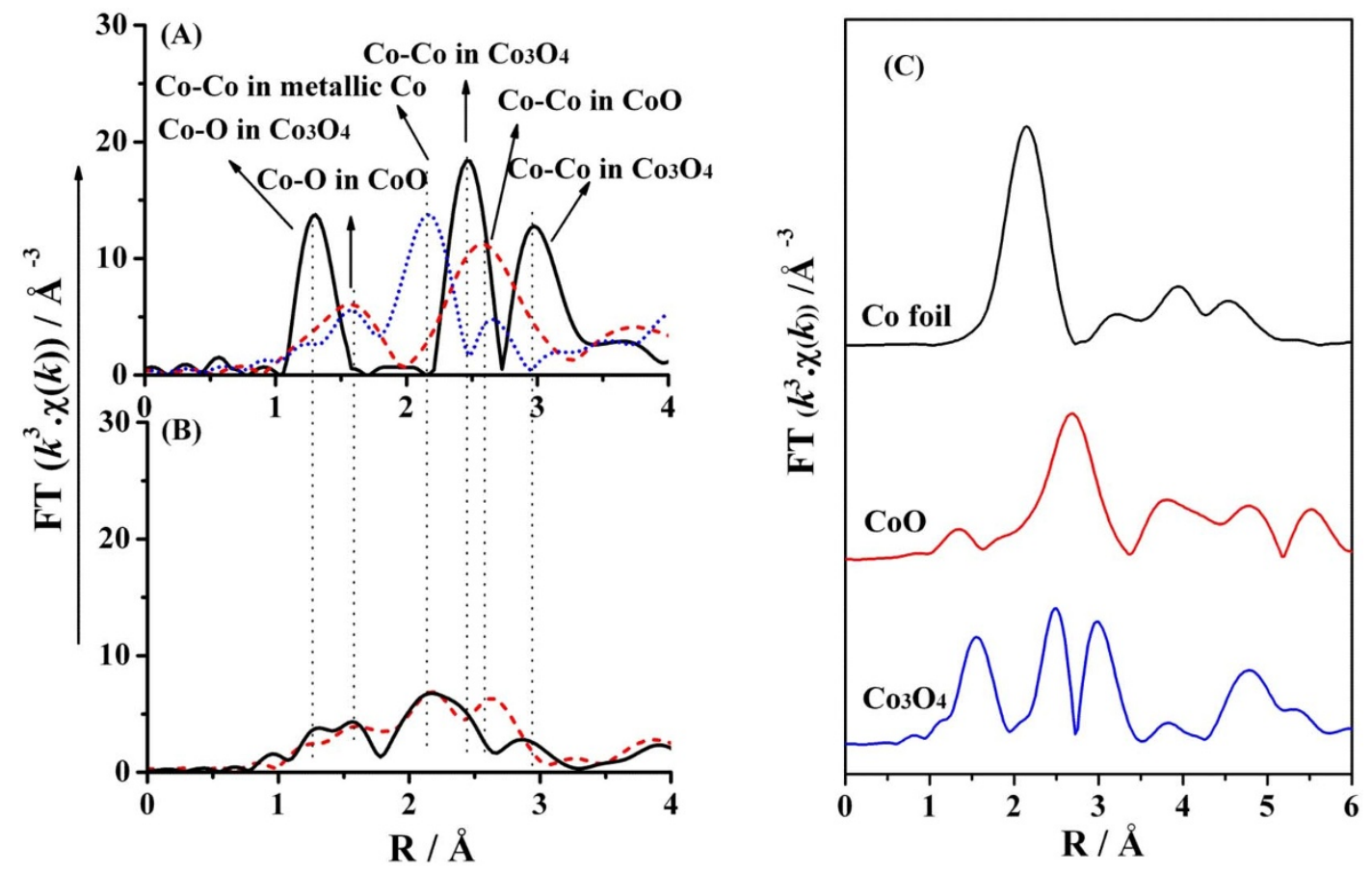

Figure 3 RSFs of the Co K-edge of the Co/H-ZSM5-I (A) and Co/H-ZSM5-S (B) catalysts: the fresh catalyst (solid line); the catalyst reduced in $\mathrm{H}_{2}$ at $260^{\circ} \mathrm{C}$ for $1 \mathrm{~h}$ (dash line); and the catalyst reduced in $\mathrm{H}_{2}$ at $400^{\circ} \mathrm{C}$ for $10 \mathrm{~h}$ (dot line); and the standard cobalt samples (C).

particles seriously aggregated, and randomly deposited on the $\mathrm{H}$ ZSM5 support with the size range of $10-30 \mathrm{~nm}$, whereas the cobalt particles of the Co/H-ZSM5-S catalyst homogeneously distributed on the H-ZSM5 surface with the narrow size range of 2-4 $\mathrm{nm}$.

The $\mathrm{H}_{2}$ Temperature-Programmed Reduction ( $\mathrm{H}_{2}$-TPR) profiles of the catalysts are presented as Supplementary Fig. S3 online. Herein, the $\mathrm{H}_{2}$-TPR profiles of the both cobalt catalysts presented two reduction peaks due to $\mathrm{Co}_{3} \mathrm{O}_{4} \rightarrow \mathrm{CoO}$ and $\mathrm{CoO} \rightarrow \mathrm{Co}^{024,25}$. It is worth to note that the initial reduction temperature of the cobalt oxides on the sputtered catalyst was about $80^{\circ} \mathrm{C}$ lower than that on the impregnated one indicating that the former had a better reducibility.

The results of the X-ray Absorption Near Edge Structures (XANES) show that for the unreduced Co/H-ZSM5-I catalyst the Co species existed in the form of $\mathrm{Co}_{3} \mathrm{O}_{4}$, while for the unreduced $\mathrm{Co} /$ $\mathrm{H}$-ZSM5-S catalyst the Co species was composed of metallic $\mathrm{Co}, \mathrm{CoO}$ and probable $\mathrm{Co}_{3} \mathrm{O}_{4}$ (see Supplementary Fig. $\mathrm{S} 4$ online). Fig. 3 shows the Radial Structure Functions (RSFs) determined by Extended Xray Absorption Fine Structures (EXAFS) of the catalysts with the various pretreatments and the standard cobalt samples as well. As shown in Fig. 3A, for the fresh Co/H-ZSM5-I catalyst, the cobalt species existed as $\mathrm{Co}_{3} \mathrm{O}_{4}$; after it was reduced in $\mathrm{H}_{2}$ at $260^{\circ} \mathrm{C}$ for $1 \mathrm{~h}$ (catalyst denoted as $\mathrm{Co} / \mathrm{H}-\mathrm{ZSM} 5-\mathrm{I}-260$ ), the cobalt species was mainly in the form of $\mathrm{CoO}$; after increasing the reduction temperature to $400^{\circ} \mathrm{C}$ and prolonging for $10 \mathrm{~h}$ (catalyst denoted as $\mathrm{Co} / \mathrm{H}$ ZSM5-I-400), the metallic cobalt became the dominant species. In Fig. 3B, the presence of the metallic species in the fresh Co/H-ZSM5$\mathrm{S}$ catalyst was clearly observed. After the catalyst was reduced in $\mathrm{H}_{2}$ at $260^{\circ} \mathrm{C}$ for $1 \mathrm{~h}$ (denoted as Co/H-ZSM5-S-260), the metallic cobalt and $\mathrm{CoO}$ were the major species. Furthermore, the magnitude of the coordination peak of the Co/H-ZSM5-S catalyst is much weaker than that of the $\mathrm{Co} / \mathrm{H}-\mathrm{ZSM} 5$-I catalyst, demonstrating that the former has a smaller coordination number and a higher disorder degree. Here, all of the EXAFS signals were ex situ recorded in air. The metallic Co nanoparticles on the Co/H-ZSM5-S and Co/H-ZSM5-S-260 catalysts were readily oxidized in air due to their small sizes and crystal defects (low coordination number). Consequently, the cobalt oxides were identified in Fig. 3B.
The qualitative contents of the cobalt compounds in the catalysts were achieved by simulation of the XANES spectra and the simulated results can be found as Supplementary Table S1 online. Clearly, a mixture of $\mathrm{Co}^{\circ}, \mathrm{CoO}$ and $\mathrm{Co}_{3} \mathrm{O}_{4}$ was deposited on the fresh $\mathrm{Co} / \mathrm{H}-$ ZSM5-S catalyst. The presence of the cobalt oxides was due to the oxidation of the sputtered metallic cobalt nano-particles during the stabilization treatment in $1 \% \mathrm{O}_{2}$ and further exposure in air, as well. For the Co/H-ZSM5-S-260 catalyst, the $\mathrm{Co}_{3} \mathrm{O}_{4}$ species disappeared, and only $\mathrm{Co}^{0}$ and $\mathrm{CoO}$ were detected. $\mathrm{Co}_{3} \mathrm{O}_{4}$ and $\mathrm{CoO}$ were the primary compounds for the fresh $\mathrm{Co} / \mathrm{H}-\mathrm{ZSM} 5-\mathrm{I}$ and $\mathrm{Co} / \mathrm{H}-\mathrm{ZSM} 5-$ I-260 catalysts, respectively; and, the metallic cobalt species only appeared on the Co/H-ZSM5-I-400 catalyst.

To illuminate the effective $\mathrm{Co}^{0}$ centers under the reducing conditions, the spectra of in situ Diffuse Reflectance Infrared Fourier Transform Spectroscopy (DRIFTS) of the Co/H-ZSM5-S-260, Co/ H-ZSM5-I-260 and Co/H-ZSM5-I-400 catalysts were recorded (see Supplementary Fig. S5 online). Much more chemisorbed CO on $\mathrm{Co}^{0}$ species (1995 and $\left.1872 \mathrm{~cm}^{-1}\right)^{26}$ was observed on the Co/H-ZSM5-S260 catalyst than that on the Co/H-ZSM5-I-400 (see Supplementary Fig. S5 online). It demonstrates that the former possessed much more active $\mathrm{Co}^{0}$ sites. Moreover, combining with the XRD results (see Supplementary Fig. S1 online), the DRIFTS results implied that the $\mathrm{Co}^{0}$ nano-particles, the effective $\mathrm{CO}$ adsorption center, was well dispersed over the zeolite surface for the Co/H-ZSM5-S-260 catalyst.

The elemental surface analysis of the catalysts without any reduction treatment was determined by X-ray Photoelectron Spectroscopy (XPS), and the details can be found as Supplementary Table S2 online. About 8.0 atm.\% cobalt, i.e. 21.0 wt.\% cobalt elements was detected on the surface of the Co/H-ZSM5-S catalyst, while only 7.1 wt.\% of cobalt was detected on the surface of the Co/H-ZSM5I catalyst. The cobalt content on the Co/H-ZSM5-S catalyst greatly exceeds the theoretical value, i.e. 7.0 wt.\%. This enrichment is due to the physical anchor of the cobalt nano-particles on the external surface of the zeolite by sputtering with weak MSI. It was reported that only the easily reducible cobalt particles on the external surface of the zeolite support were the active sites for $\mathrm{FTS}^{27}$. Herein, the readily reducible cobalt nano-particles on the Co/H-ZSM5-S catalyst were homogeneously wedged on the external surface of the H-ZSM5 with 
Table 1 | Catalytic performance of the Co/H-ZSM5 catalysts for the direct synthesis of iso-paraffin

\begin{tabular}{lcccccccc|} 
& & \multicolumn{2}{c}{ Selectivity (\%) } & & & & \\
\cline { 3 - 4 } Catalysts & Co Conversion (\%) & $\mathrm{CH}_{4}$ & $\mathrm{CO}_{2}$ & & $\mathrm{C}_{\text {iso }} / \mathrm{C}_{\mathrm{n}}$ (n $\left.\geq 4\right)$ & $\mathrm{C}_{1} \sim \mathrm{C}_{4}$ (mol\%) & $\mathrm{C}_{5} \sim \mathrm{C}_{11}$ (mol\%) & $\mathrm{C}_{12+}$ (mol\%) \\
\hline Co/H-ZSM5--260 & 35.1 & 26.2 & 0.1 & 1.1 & 63.2 & 35.8 & 1.0 \\
Co/H-ZSM5--1-400 & 64.1 & 25.1 & 0.9 & 0.8 & 51.8 & 46.3 & 1.9 \\
Co/H-ZSM5-S-260 & 75.2 & 15.2 & 2.4 & 2.2 & 25.8 & 67.3 & 6.9 \\
\hline
\end{tabular}

more exposed edges, corners and faces as compared with the $\mathrm{Co} / \mathrm{H}-$ ZSM5-I catalyst. Thus, these differences probably resulted in a better FTS performance. Moreover, the high dispersion and enrichment of the cobalt nano-particles on the surface of the H-ZSM5 would increase the chance for the produced long chain $n$-paraffin products therein to be captured by the adjacent acidic sites on the H-ZSM5 support. This is beneficial to the production of iso-paraffin.

Catalytic performance. To certify our assumption, the catalytic activities of the Co/H-ZSM5-I and Co/H-ZSM5-S catalysts were compared for the direct synthesis of iso-paraffin from syngas. The obtained catalytic performances are listed in Table 1 , and the product distributions are given in Fig. 4. It shows clearly that the $\mathrm{CH}_{4}$ selectivity is in the sequence of Co/H-ZSM5-I-260 > Co/H-ZSM5I-400 $>$ Co/H-ZSM5-S-260, while the tendency of the CO conversion is on the contrary. Moreover, the Co/H-ZSM5-S-260 catalyst provides the highest iso-paraffin selectivity among these catalysts, and its molar ratio of iso- to $n$-paraffin in the products $\left(\geq \mathrm{C}_{4}\right)$ reaches 2.2. The similar trend was observed over the $\mathrm{Co} / \mathrm{H}-$ ZSM5 catalysts with the $2.2 \mathrm{wt} \%$ cobalt loading (see Supplementary Table. S3 online).

The pyridine FT-IR spectra of the H-ZSM5 support, Co/H-ZSM5S-260 and Co/H-ZSM5-I-400 catalysts see Supplementary Fig. S6 online. The amount of the Brønsted acid sites on both cobalt supported catalyst is smaller than that of the H-ZSM5 support. The Co/ H-ZSM5-S-260 catalyst had the similar amount of Brønsted acid sites with the Co/H-ZSM5-I-400 catalyst, but the cobalt nano-particles were highly dispersed on the former one, which increased the chance for the formed $n$-paraffin to be captured by the adjacent acidic sites. Thus, it resulted in a much better isomerization and hydrocracking performances. Additionally, the much higher ratio of the Brønsted to Lewis acid sites of the Co/H-ZSM5-S-260 catalyst, as compared with the Co/H-ZSM5-I-400 here, might be beneficial to the isomerization and hydrocracking of $n$-paraffin on the H-ZSM-5 support ${ }^{8}$, as well.

Usually, the unreduced cobalt oxides will cause the high $\mathrm{CH}_{4}$ selectivity and the low $\mathrm{CO}$ conversion ${ }^{3}$. The large-size metal catalysts have weak MSI and excellent reducibilities compared with the small ones $^{28}$. Here, the Co/H-ZSM5-S-260 catalyst has the higher CO conversion and the lower $\mathrm{CH}_{4}$ selectivity than the Co/H-ZSM5-I-400 catalyst. It indicates that the Co/H-ZSM5-S-260 catalyst possesses much more active cobalt FTS sites. It is in good agreement with the in situ DRIFTS results (see Supplementary Fig. S5 online). Moreover, the selectivity of the $\mathrm{C}_{5}-\mathrm{C}_{11}$ products of the $\mathrm{Co} / \mathrm{H}-\mathrm{ZSM} 5-\mathrm{S}-260$ catalyst is around 67\%, much higher than that is predicted by the ASF law (about $45 \%{ }^{3}$ ), and the proportion of the $\mathrm{C}_{5}-\mathrm{C}_{11}$ range iso-paraffin products is about $60 \%$. Undoubtedly, this increases the octane number of the oil products greatly. The high selectivity of the gasoline range iso-paraffin here is due to the in situ isomerization and hydrocracking of the long chain $n$-paraffin at the acidic sites of the $\mathrm{H}$ ZSM5 surrounding the cobalt. These findings demonstrate that the utilization of the combined cobalt and H-ZSM5 bifunctional catalyst synthesized by the physical-sputtering method is an effective way to produce synthetic premier gasoline from syngas directly by a synergistic way. After the reaction, little wax was deposited on the Co/H-ZSM5-S-260 catalyst (see Supplementary Fig. S7, S8 online). Thus, little change on the acidic property of the fresh and used
Co/H-ZSM5-S-260 catalysts was observed from the FT-IR spectra for pyridine adsorption (see Supplementary Fig. S9 online). On the contrary, the intensity of the IR bands for both Brønsted and Lewis acid sites seriously dropped for the used Co/H-ZSM5-I-400, probably due to the formation of waxy hydrocarbons therein, considering weaker hydrocracking ability of the Co/H-ZSM5-I-400.

\section{Discussion}

Directly depositing cobalt on the acidic catalysts, such as zeolite, typically has the lower activity for the straightforward synthesis of the gasoline range iso-paraffin than using the separately loaded FTS and acidic catalysts ${ }^{12,13,29}$. The hindrance is mainly due to the low reduction degree of the supported metal catalyst determined by the strong MSI and the spatial arrangement of the FTS-active sites and acidic sites. The bifunctional H-ZSM5-supported cobalt nano-catalyst synthesized by the dry physical-sputtering method introduced herein showed the much higher catalytic performances than the conventional catalyst. This catalyst possesses the homogeneous distribution of the cobalt nano-particles with the narrow size range and high dispersion. Furthermore, the cobalt nano-particles are readily reduced to the metallic state due to the weak MSI. This methodology is not only beneficial to synthesis of the gasoline range iso-paraffin herein, but also provides a new strategy to avoid a negative effect on other catalytic processes resulting from the strong MSI.

\section{Methods}

Catalyst preparation. The H-ZSM5 support (Süd-Chemie catalyst Co. Ltd., H-MFI$90,362.3 \mathrm{~m}^{2} \mathrm{~g}^{-1}, \mathrm{SiO}_{2} / \mathrm{Al}_{2} \mathrm{O}_{3}=83.7$ in molar ratio) was calcined at $400^{\circ} \mathrm{C}$ for $2 \mathrm{~h}$ before utilization. For the $\mathrm{Co} / \mathrm{H}-\mathrm{ZSM} 5-\mathrm{S}$ catalyst, the metallic cobalt nano-particles were sputtered onto the pretreated H-ZSM5 powder with a metallic Co sputtering target (purity $99.9 \%, 5 \mathrm{~cm} \times 10 \mathrm{~cm}$ ) in a polygonal barrel-sputtering equipment ${ }^{17}$. The vacuum chamber was carefully evacuated to $8.0 \times 10^{-4} \mathrm{~Pa}$, followed by introducing a pure Ar flow (purity: $99.995 \%$, flow rate $=29 \mathrm{~mL} \mathrm{~min}^{-1}$ ) into the chamber until the pressure reached 2.0 Pa. A generated Ar plasma was used to attack the Co target and to sputter Co clusters onto the H-ZSM5 surface (input power $400 \mathrm{~W}$, frequency $13.56 \mathrm{MHz} \pm 5 \mathrm{KHz}$, rotating rate $3.5 \mathrm{rpm}$ ). The whole experiment took $170 \mathrm{~min}$, and $7.0 \mathrm{wt} \%$ of cobalt was loaded onto the H-ZSM5 powder. Thereafter, a $1.0 \% \mathrm{O}_{2} / \mathrm{N}_{2}$ flow (flow rate $=29 \mathrm{~mL} \mathrm{~min}^{-1}$ ) was gradually

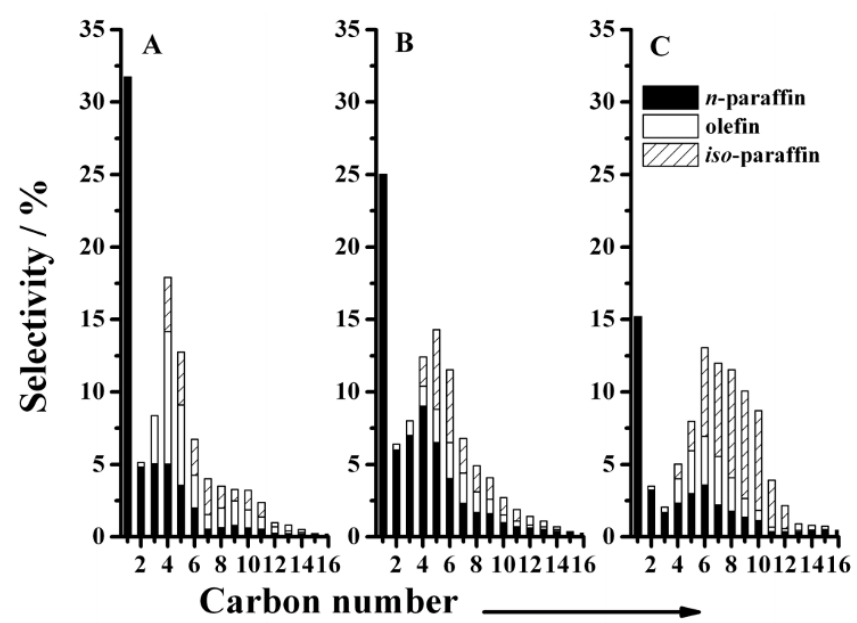

Figure $4 \mid$ Product distributions over the catalysts: (A) Co/H-ZSM5-I260; (B) Co/H-ZSM5-I-400; and (C) Co/H-ZSM5-S-260. 
introduced into the vacuum chamber to reach the atmosphere pressure, and kept for $1 \mathrm{~h}$ to stabilize the metallic cobalt supported catalyst before exposure in air.

For the Co/H-ZSM5-I catalyst, a certain amount of $\mathrm{Co}\left(\mathrm{NO}_{3}\right)_{2} \cdot 6 \mathrm{H}_{2} \mathrm{O}$ was dissolved in distilled water, followed by impregnation of the aqueous solution onto $5.0 \mathrm{~g}$ of the H-ZSM5 powder by a conventional incipient wetness impregnation method. This precursor was then dried overnight at $70^{\circ} \mathrm{C}$ under vacuum, and calcined at $400^{\circ} \mathrm{C}$ for $2 \mathrm{~h}$ to decompose nitrate completely. The weight percentage of the loaded cobalt was 7.0 wt.\%.

Before reaction, the catalysts were in situ reduced by hydrogen at the specific temperature $\left(260^{\circ} \mathrm{C}\right.$ for $1 \mathrm{~h}$ or $400^{\circ} \mathrm{C}$ for $\left.10 \mathrm{~h}\right)$ inside the high-pressure flow-type reactor.

Catalyst characterization. The HR-TEM images were taken with a Philips Tecnai G2F20 instrument operating at $200 \mathrm{kV}$. XAFS signals of the Co K-edge were collected using a fluorescence mode at 14W1 beamline of the Shanghai Synchrotron Radiation Facility (SSRF). The storage ring was operated at $3.5 \mathrm{GeV}$ with a current of $\sim 250 \mathrm{~mA}$. A Si (111) double-crystal monochromator was used to reduce the harmonic content in the source beam. The RSFs was achieved by Fourier transforming of the $k^{3}$ weighted EXAFS data in the range of $k=3.1-13.1 \AA^{-1}$ using a Bessel function window.

Catalytic testing. The FTS reaction was carried out with a continuous flowing fixedbed reactor from syngas ( $\mathrm{Ar}: 3.0 \%, \mathrm{CO}: 32.3 \%$, balance with $\mathrm{H}_{2}$ ). Behind the reactor, an ice trap with the solvent and inner standard was equipped to capture the heavy hydrocarbons in the effluent. $0.5 \mathrm{~g}$ of the catalyst was used here. Reaction conditions were $260^{\circ} \mathrm{C}, 1.0 \mathrm{MPa}$, and $\mathrm{W}_{\text {catalyst }} / \mathrm{F}=10 \mathrm{~g} \mathrm{~h} \mathrm{~mol}^{-1}$. Briefly, the effluent gas released from the reactor was analyzed by an on-line gas chromatograph (Shimadzu, GC-8A) using an active charcoal column equipped with a TCD. The products of light hydrocarbons $\left(\mathrm{C}_{1}-\mathrm{C}_{10}\right)$ were also analyzed by an online gas chromatograph (GCFID, Shimadzu, GC-14B) with a capillary column (J\&W Scientific GS-Alumina, i.d. $0.53 \mathrm{~mm}$, length $=30 \mathrm{~m}$ ) to separate iso-paraffin and $n$-paraffin. The products with a carbon number higher than 10 were analyzed by a high temperature distillation-type gas chromatograph (HP-6890)

Each reaction was continuously implemented for $20 \mathrm{~h}$ time-on-stream and the activity generally reached maximum during $1^{\text {st }}-5^{\text {th }} \mathrm{h}$ and then became stable.

1. Vannice, M. A. The catalytic synthesis of hydrocarbons from carbon monoxide and hydrogen. Catal. Rev. - Sci. Eng. 14, 153-191 (1976).

2. Chum, H. L. \& Overend, R. P. Biomass and renewable fuels. Fuel Proc. Technol. 71, 187-195 (2001).

3. Zhang, Q., Kang, J. \& Wang, Y. Development of novel catalysts for FischerTropsch synthesis: tuning the product selectivity. ChemCatChem 2, 1030-1058 (2010).

4. Roy, S. \& Baiker, A. NOx storage-reduction catalysis: from mechanism and materials properties to storage-reduction performance. Chem. Rev. 109, 4054-4091 (2009)

5. Henrici-Olivé, G. \& Olivé, S. The Fischer-Tropsch synthesis: molecular weight distribution of primary products and reaction mechanism. Angew. Chem. Int. Ed. 15, 136-141 (1976).

6. Eilers, J., Posthuma, S. A. \& Sie, S. T. The shell middle distillate synthesis process (SMDS). Catal. Lett. 7, 253-269 (1990).

7. Ge, Q., Huang, Y., Qiu, F. \& Li, S. Bifunctional catalysts for conversion of synthesis gas to dimethyl ether. Appl. Catal. A 167, 23-30 (1998).

8. Feller, A., Guzman, A., Zuazo, I. \& Lercher, J. A. On the mechanism of catalyzed isobutane/butene alkylation by zeolites. J. Catal. 224, 80-93 (2004).

9. Tsubaki, N., Yoneyama, Y., Michiki, K. \& Fujimoto, K. Three-component hybrid catalyst for direct synthesis of isoparaffin via modified Fischer-Tropsch synthesis. Catal. Commun. 4, 108-111 (2003).

10. Liu, Z., Li, X., Asami, K. \& Fujimoto, K. High performance Pd/beta catalysts for the production of gasoline-range iso-paraffins via a modified Fischer-Tropsch reaction. Appl. Catal. A 300, 162-169 (2006).

11. Yoneyama, Y., Morii, Y., He, J. \& Tsubaki, N. Direct synthesis of isoparaffin by modified Fischer-Tropsch synthesis using hybrid catalyst of iron catalyst and zeolite. Catal. Today 104, 37-40 (2005).

12. Chen, Y. W., Tang, H. T. \& Goodwin, J. G. Effect of preparation methods on the catalytic properties of zeolite-supported ruthenium in the Fischer-Tropsch synthesis. J. Catal. 83, 415-427 (1983).

13. Nijs, H. H. \& Jacobs, P. A. New evidence for the mechanism of the FischerTropsch synthesis of hydrocarbons. J. Catal. 66, 401-411 (1980).

14. Sun, B. et al. Fischer-Tropsch synthesis over molecular sieve supported catalysts. ChemCatChem 3, 542-550 (2011).
15. Resini, C. et al. Selective catalytic reduction of $\mathrm{NO}_{\mathrm{x}}$ by methane over Co-H-MF and Co-H-FER zeolite catalysts: characterization and catalytic activity. J. Catal. 214, 179-190 (2003).

16. He, J. et al. Multiple-functional capsule catalysts: A tailor-made confined Reaction environment for the direct synthesis of middle isoparaffins from syngas. Chem. Eur. J. 12, 8296-8304 (2006).

17. Bao, J. et al. A Core/Shell catalyst produces a spatially confined effect and shape selectivity in a consecutive reaction. Angew. Chem. Int. Ed. 47, 353-356 (2008).

18. $\mathrm{Li}$, X. et al. One-step synthesis of $\mathrm{H}$-beta zeolite enwrapped $\mathrm{Co} / \mathrm{Al}_{2} \mathrm{O}_{3}$ FischerTropsch catalyst with high spatial selectivity. J. Catal. 265, 26-34 (2009).

19. Abe, T. et al. Surface modification of polymer microparticle using a hexagonalbarrel sputtering system. J. Alloy. Compd. 402, 227-232 (2005).

20. Yamamoto, H., Hirakawa, K. \& Abe, T. Surface modification of carbon nanofibers with platinum nanoparticles using a "polygonal barrel-sputtering" system. Mater. Lett. 62, 2118-2121 (2008).

21. Inoue, M. et al. Preparation and physical and electrochemical properties of carbon-supported $\mathrm{Pt}-\mathrm{Ru}(\mathrm{Pt}-\mathrm{Ru} / \mathrm{C})$ samples using the polygonal barrel-sputtering method. J. Phys. Chem. C 112, 1479-1492 (2008).

22. Abe, T. et al. $\mathrm{CO}_{2}$ methanation property of Ru nanoparticle-loaded $\mathrm{TiO}_{2}$ prepared by a polygonal barrel-sputtering method. Energy Environ. Sci. 2, 315-321 (2009).

23. Hirakawa, K., Inoue, M. \& Abe, T. Methanol oxidation on carbon-supported Pt$\mathrm{Ru}$ and $\mathrm{TiO}_{2}\left(\mathrm{Pt}-\mathrm{Ru} / \mathrm{TiO}_{2} / \mathrm{C}\right)$ electrocatalyst prepared using polygonal barrelsputtering method. Electrochim. Acta 55, 5874-5880 (2010).

24. Ishihara, T., Eguchi, K. \& Arai, H. Hydrogenation of carbon monoxide over $\mathrm{SiO}_{2-}$ supported Fe-Co, $\mathrm{Co}-\mathrm{Ni}$ and Ni-Fe bimetallic catalysts. Appl. Catal. 30, 225-238 (1987).

25. Duvenhage, D. J. \& Coville, N. J. Fe:Co/TiO ${ }_{2}$ bimetallic catalysts for the FischerTropsch reaction 1. Characterization and reactor studies. Appl. Catal. A 153, 43-67 (1997).

26. Morales, F. et al. Effects of manganese oxide promoter on the $\mathrm{CO}$ and $\mathrm{H}_{2}$ adsorption properties of titania-supported cobalt Fischer-Tropsch catalysts. J. Catal. 246, 91-99 (2007).

27. Ngamcharussrivichai, C., Imyim, A., Li, X. \& Fujimoto, K. Active and selective bifunctional catalysts for gasoline production through a slurry-phase FischerTropsch synthesis. Ind. Eng. Chem. Res. 46, 6883-6890 (2007).

28. Soled, S. L. et al. Control of metal dispersion and structure by changes in the solidstate chemistry of supported cobalt Fischer-Tropsch catalysts. Top. Catal. 26, 101-109 (2003).

29. Zhao, T., Chang, J., Yoneyama, Y. \& Tsubaki, N. Selective synthesis of middle isoparaffins via a two-stage Fischer-Tropsch reaction: activity investigation for a hybrid catalyst. Ind. Eng. Chem. Res. 44, 769-775 (2005).

\section{Acknowledgements}

Authors thank support from National Natural Science Foundation of China (No. U1162103), Tianjin Sci. \& Tech. Support Program (No. 09ZCGHHZ00400, No. 11JCYBJC03700), the Program for New Century Excellent Talents in University of China (NCET-10-0615), and Foundation of State Key Lab. of Coal Conversion (No. J12-13-902). Partial supports from Program for Introducing Talents of Discipline to Universities of China (No. B06006) and the Key Laboratory for Green Chemical Technology of Ministry of Education (Tianjin University) are also greatly acknowledged. Financial aids from NEDO and JOGMEC, Japan are highly appreciated.

\section{Author contributions}

X.-G.L. and N.T. designed the experiments, C.L., J.S., H.X. and Y.Y. carried out the experiments, A.T., M.I. and T.A. prepared the sputtered catalysts, Z.J. helped to collect XAFS data, X.-G.L., N.T. and Y.-S.T. analyzed the experimental data, X.-G.L., N.T. and T.A wrote the manuscript. All the authors participated in discussions of the research.

\section{Additional information}

Supplementary information accompanies this paper at http://www.nature.com/ scientificreports

Competing financial interests: The authors declare no competing financial interests.

How to cite this article: Li, X. et al. Tuning interactions between zeolite and supported metal by physical-sputtering to achieve higher catalytic performances. Sci. Rep. 3, 2813; DOI:10.1038/srep02813 (2013).

This work is licensed under a Creative Commons AttributionNonCommercial-NoDerivs 3.0 Unported license. To view a copy of this license, visit http://creativecommons.org/licenses/by-nc-nd/3.0 